http://ojs.stikes-muhammadiyahku.ac.id/index.php/herbapharma

\title{
FORMULASI SIRUP ANTIDIARE EKSTRAK ETHANOL BUAH HARENDONG (Melastoma malabathricum L.) DENGANGELATIN DAN NATRIUM CARBOXYMETHIL CELULLOSE SEBAGAI PENGENTAL
}

\section{Sri Wahyuni, Imas Maesaroh}

Program Studi Farmasi, STIKes Muhammadiyah Kuningan

*E-mail : wsri4923@gmail.com

\begin{abstract}
ABSTRAK
Ekstrak etanol $96 \%$ buah harendong 50\% telah terbukti memiliki efektivitas antidiare. Salah satu untuk memudahkan penggunaan maka di buat sediaan sirup. Gelatin dan natriumCarboxymethilcelullose digunakan sebagai pengental untuk meningkatkan viskositas sirup. Penelitian ini bertujuan untuk mengetahui konsentrasi formula sirup antidiare ekstrak etanol buah harendong (Melastoma malabathricum L.) dengan variasi gelatin dan natrium carboxymethilcellulosa sebagai pengental yang paling baik secara sifat fisika (uji organoleptis, uji homogenitas, uji bobot jenis, dan uji viskositas) dan sifat kimia (uji pH). F1 menggunakan pengental gelatin 3\%, F2 menggunakan natrium carboxymethilcelullose $0,3 \%$, F3 menggunakan pengental gelatin $2 \%$ dan natrium carboxymethilcelullose $0,2 \%$. Hasil penelitian uji organoleptis ketiga formula tersebut yaitu warna ungu pekat, memiliki bau khas buah harendong, dan rasa manis. Hasil uji homogenitas yaitu F1 tidak homogen, F2 homogen dan F3 tidak omogen. Hasil bobot jenis yang di peroleh yaitu F1 $1,071 \mathrm{~g} / \mathrm{ml}$, F2 $1,021 \mathrm{~g} / \mathrm{ml}$, F3 $1,046 \mathrm{~g} / \mathrm{ml}$. Hasil uji viskositas yang paling tinggi adalah F3 dengan hasil $13,49 \mathrm{cps}$ dibanding F1 dengan hasil $11,24 \mathrm{cps}$, dan F2 11,18 cps. Hasil dari uji pH F1, F2, dan $\mathrm{F} 3$ yaitu $\mathrm{pH}$ 5. Konsentrasi formula yang terbaik yaitu F3, meskipun belum memenuhi standar yang ditentukan, tetapi hasil uji secara sifat fisika dan sifat kimia dari F3 ini mendekati dari standar ketentuan.
\end{abstract}

Kata Kunci :Ekstrak buah harendong, Gelatin, Natrium carboxymethilcelullose.

\section{ABSTRACT}

Ethanol extract $96 \%$ harendong fruit $50 \%$ has been shown to have antidiarrhoea effectiveness. One to facilitate the use of syrup. Gelatin and sodium Carboxymethilcelullose are used as thickeners to increase the viscosity of the syrup. This research aims to find out the concentration of the antidiarrhoea syrup formula of harendong fruit ethanol extract (Melastoma malabathricum L.) with variations of gelatin and sodium carboxymethilcellulosa as the best thickeners by physical properties (organoleptic test, homogeneity test, type weight test, and viscosity test) and chemical properties ( $\mathrm{pH}$ test). F1 uses a 3\% gelatin thickener, F2 uses $0.3 \%$ carboxymethilcelullose sodium, F3 uses a $2 \%$ gelatin thickener and $0.2 \%$ sodium carboxymethilcelullose. The results of the third organoleptic test of the formula are a deep purple color, have a distinctive smell of harendong fruit, and sweetness. Homogeneity test results i.e. F1 is not homogeneous, F2 homogeneous and F3 is not omogen. The result of the type weight obtained is $F 11,071 \mathrm{~g} / \mathrm{ml}, F 21,021 \mathrm{~g} / \mathrm{ml}, F 31,046 \mathrm{~g} / \mathrm{ml}$. The highest viscosity test results were F3 with $13.49 \mathrm{cps}$ compared to F1 with $11.24 \mathrm{cps}$, and F2 $11.18 \mathrm{cps}$. The results of the $\mathrm{F1}, \mathrm{F} 2$, and $\mathrm{F} 3 \mathrm{pH}$ tests are $\mathrm{pH}$ 5. The best concentration of formulas is $\mathrm{F} 3$, although it does not meet the specified standards, but the test results of the physical properties and chemical properties of this $\mathrm{F} 3$ are close to the standard stipulation. 
Keywords :Harendong fruit extract, Gelatin, Sodium carboxymethilcelullose.

\section{PENDAHULUAN}

Kekayaan alam Indonesia, memiliki berbagai tumbuhan yang berkhasiat obat dari 40 ribu jenis flora yang tumbuh di dunia, dan 30 ribu diantaranya ada di Indonesia. Dari 30 ribu flora yang ada di Indonesia, $74 \%$ diantaranya tumbuh liar di hutandan $26 \%$ sudah dibudidayakan.Lebih dari 20 ribu spesies tumbuhan berkhasiat obat digunakan oleh penduduk di seluruh didunia (Arsyah, 2014).

Tanaman harendong telah banyak digunakan sebagai obat tradisional di beberapa daerah di Indonesia. Tanaman harendong dengan nama latin yaitu Melastoma malabathricum L. tumbuh sebagai tanaman liar. Di Kabupaten Kuningan (Wilayah Taman Nasional Gunung Ciremai) buah harendong dimanfaatkan sebagai pengobatan diare (Salsabila, 2014).Penelitian yang dilakukan oleh Kiki bahwa ekstrak etanol $98 \%$ buah harendong mentah dengan konsentrasi ekstrak $50 \%$ memiliki efek antidiare yang lebih kuat dibanding dengan loperamid $\mathrm{HCl}$. (Kiki, 2018).

Diare adalah penyakit yang ditandai dengan peningkatan massa feses, frekuensi defekasi ( $\geq 3$ kali per kali ) atau fluiditas (tingkat keenceran) (Robbins, 2007). Menurut catatan WHO, diare membunuh dua juta anak di dunia setiap tahun. Sebagian dari penderita $(1-2 \%)$ akan mengalami dehidrasi dan jika tidak segera ditolong $50-60 \%$ diantaranya dapat meninggal (Noerasid; Suraatmadja, 2003).

Diare ini sering terjadi pada bayi dan balita, yang tidak memungkinkan untuk menelan sediaan dalam bentuk kapsul dan tablet serta membutuhkan sediaan yang memiliki hasil efek yang cepat. Sirup adalah salah satu yang memenuhi kriteria sediaan yang dibutuhkan oleh bayi dan balita.Namun dalam pengembangan obat herbal untuk menjadi sediaan sirup memiliki kendala yang sering ditemui yaitu sulit menghasilkan sediaan yang memenuhi syarat sifat fisika dan kimia karena berpengaruh terhadap bioavailabilitas bahan aktif obat.

Ekstrak cair dan kental dapat digunakan untuk membuat sediaan cair. Namun ekstrak memiliki sifat yang sukar larut dalam larutan karena dapat terdispersi membentuk partikel kasar, oleh karena itu dalam pembuatan sediaan sirup dibutuhkan bahan pengental (Rowe C. 2009). Penggunaan bahan pengental pada sirup dilakukan untuk meningkatkan viskositas dan memperlambat atau menahan proses pengendapan sehingga menghasilkan sirup yang stabil (Nash, 1996).

\section{BAHAN DAN METODE}

\section{Bahan dan Alat}

Bahan berkhasiat yang digunakan adalah ekstrak etanol buah harendong (Melastoma malabthricum L.). Pelarut yang digunakan adalah etanol $96 \%$. Bahan - bahan yang digunakan dalam pembuatan sirup ini adalah serbuk simplisia buah harendong (Melastoma malabthricum L.), etanol 96\%, natrium carboxymethilcelullose, gliserin, sukrosa, gelatin, methil paraben, essense, aquadest. Alat yang digunakan untuk pembuatan ekstrak etanol buah harendong dengan metode maserasi diantara lain, maserator, gelas ukur, timbangan analitik, beakerglass, batang pengaduk, kain flanel, cawan, dan waterbath. Sedangkan alat - alat untuk pembuatan dan evaluasi sediaan sirup adalah botol kaca $60 \mathrm{ml}$, mortir stemper, beakerglass, gelas ukur, kaca arloji, cawan, viknometer ostwald, piknometer, $\mathrm{pH}$ universal.

\section{Jenis Penelitian}

Penelitian ini menggunakan jenis penelitian eksperimental research

\section{Prosedur Penelitian}

\section{Esktraksi Buah Harendong}


Dilakukan ekstraksi menggunakan metode maserasi. Timbang serbuk buah harendong mentah sebanyak 200 gram menggunakan timbangan analitik. Kemudian ekstraksi serbuk buah harendong menggunakan metode maserasi dengan pelarut etanol $96 \%$ selama $5 \times 24$ jam dengan 8 jam sekali pengadukan. Pada $3 \times 24$ jam baru dilakukan filtrasi pertama menggunakan kain fllanel, dan setiap 24 jam sekali di filtrasi. Setelah itu semua filtrat digabung dan dilakukan penguapan diatas waterbath sampai membentuk ekstrak kental (Kiki, 2018).

\section{Pembuatan Sirup Buah Harendong}

Tabel 1. Formula Sirup Ekstrak Etanol Buah Harendong (Melastoma malabathricum L.)

\begin{tabular}{|c|c|c|c|c|}
\hline Bahan & F1 & F2 & F3 & Fungsi \\
\hline $\begin{array}{l}\text { Ektrak Buah } \\
\text { Harendong }\end{array}$ & $50 \%$ & $50 \%$ & $50 \%$ & Zat aktif \\
\hline Sukrosa & $60 \%$ & $60 \%$ & $60 \%$ & Pemanis \\
\hline Gelatin & $3 \%$ & & $2 \%$ & Pengental \\
\hline Na. CMC & - & $0,3 \%$ & $0,2 \%$ & Pengental \\
\hline Gliserin & $5 \%$ & $5 \%$ & $5 \%$ & Pelarut \\
\hline Essense & qs & qs & qs & $\begin{array}{l}\text { Pengarom } \\
\text { a }\end{array}$ \\
\hline $\begin{array}{l}\text { Metil } \\
\text { paraben }\end{array}$ & $0,25 \%$ & $\begin{array}{l}0,25 \\
\%\end{array}$ & $0,25 \%$ & Pengawet \\
\hline Aquadest & $100 \%$ & $100 \%$ & $100 \%$ & Pelarut \\
\hline
\end{tabular}

Pembuatan sirup buah harendong pertama siapkan alat dan bahan, timbang masing masing bahan sesuai dengan formula yang terdapat pada tabel 1 . Kalibrasi botol sirup $60 \mathrm{ml}$, beri tanda. Memasukan ekstrak etanol buah harendong ke dalam mortir dan ditambah metil paraben aduk rata (masa 1).Pembuatan mucilago gelatin dan mucilago $\mathrm{Na}$. CMC dengan cara didispersikan gelatin ataupun $\mathrm{Na}$. CMC dalam sebagian gliserin dan air sampai terbentuk cairan yang kental (masa 2). (untuk F1 menggunakan gelatin, F2 menggunakan $\mathrm{Na}$. CMC dan F3 menggunakan gelatin dan $\mathrm{Na}$. CMC). Pembuatan sirup sukrosa dengan cara melarutkan sukrosa dan air dengan bantuan panas tunggu agak dingin (masa 3).Masukan masa 2 ke masa 3 lalu campurkan dengan masa 1, aduk hingga homogen.Tambahkan essense secukupnya sebagai pengaroma aduk hingga homogen. Tambahkan aquadest hingga batas kalibrasi.

\section{Evaluasi Sediaan}

\section{a. Uji Organoleptik}

Sirup ekstrak etanol buah harendong diperiksa menggunakan panca indra atau tanpa alat bantu terhadap aroma, rasa, warna sediaan (Chater, 1997).

\section{b. Uji Homogenitas}

Sirup ekstrak etanol buah harendong diperiksa dengan cara dituang pada kaca transparan, lalu bagian yang tidak tercampurkan dengan baik diamati (Charter, 1997).

\section{c. Uji Viskositas}

Pengukuran viskositas dilakukan menggunakan viskometer Ostwald. Viskositas sediaan uji dihitung menggunakan rumus sebagai berikut (Sinko, 2006). Masukan sirup sebanyak $10 \mathrm{ml}$ ke dalam viskometer. Kemudian dinaikkan menggunakan pompa hingga permukaannya berada pada bagian batas garis atas ostwald. Saat permukaan sirup sudah berada pada bagian batas bagian garis atas, pompa dilepaskan dan perhitungan waktu dengan stopwatch dimulai dan di berhentikan saat sirup sudah mencapai batas bawah bagian pompa. Kemudian catat waktu alir tersebut, dan hitung. 


$$
\text { Viskositas }=\frac{\rho \text { sampel } x \mathrm{t} \text { sampel }}{\rho \text { air suling } \mathrm{x} \text { t air suling }} \times \boldsymbol{\eta} \text { air suling }
$$

Keterangan :

$\eta=$ viskositas air suling

$\rho=$ bobot jenis larutan pada $25^{\circ} \mathrm{C}(\mathrm{g} / \mathrm{mL})$

$\mathrm{t}=$ waktu yang dibutuhkan larutan untuk mengalir pada $25^{\circ} \mathrm{C}$ (detik)

\section{d. Uji Bobot Jenis}

Penetepan bobot jenis dilakukan menggunakan piknometer yang bersih dan kering. Pada suhu ruangan, piknometer kosong $\left(w_{1}\right)$ ditimbang, lalu diisi dengan air suling, bagian luar piknometer dilap sampai kering kemudian ditimbang $\left(w_{2}\right)$. Air suling yang ada di dalam piknometer dibuang lalu dikeringkan selanjutnya piknometer yang sudah kering diisi dengan sediaan sirup kemudian ditimbang $\left(\mathrm{w}_{3}\right)$. Bobot jenis cairan dihitung dengan rumus: (Depkes RI, 1995).

$$
\rho=\frac{w_{3}-w_{1}}{w_{2}-w_{1}} \times \text { bobot jenis air }(\mathrm{g} / \mathrm{ml})
$$

Keterangan :

$\rho=$ Bobot jenis sirup

$\mathrm{w}_{1}=$ Bobot piknometer kosong

$\mathrm{w}_{2}=$ Bobot piknometer +air suling

$\mathrm{w}_{3}=$ Bobot piknometer kosong + sirup

\section{e. Uji pH}

$\mathrm{pH}$ yang digunakan adalah $\mathrm{pH}$ universal, tuangkan sediaan sirup kedalam beakerglass, lalu celupkan kertas $\mathrm{pH}$. Cocokkan warna yang dihasilkan oleh pHstripdenganindikator warna yang ada pada kemasan $\mathrm{pH}$ universal indicator.

\section{HASIL DAN PEMBAHASAN}

\section{Ekstraksi Buah Harendong}

(Melastoma malabathricum L.)dengan metode maserasi digunakan serbuk buah harendong dan pelarut etanol $96 \%$ dengan 200 gram serbuk buah harendong dimasukan ke dalam maserator lalu ditambahkan etanol $96 \%$ sampai terendam $(800 \mathrm{ml})$ dan didiamkan selama $3 \times 24$ jam sambil diaduk setiap 8 jam sekali. Maserasi dilakukan sebanyak dua kali. Filtrasi menggunakan kain flanel, hasil filtrat disatukan mendapatkan hasil $1250 \mathrm{ml}$. Setelah itu hasil filtrat tersebut diuapkan di atas waterbath sampai membentuk ekstrak kental dan didapat ekstrak kental buah harendong (Melastoma malabathricum L.) sebanyak 197 gram. 


\section{Uji Organoleptik}

Tabel 2. Hasil Uji Organoleptik

\begin{tabular}{cccc}
\hline Sirup & Warna & Rasa & Aroma \\
\hline F1 & Ungu & Manis & $\begin{array}{l}\text { Khas buah } \\
\text { harendong } \\
\text { pekat }\end{array}$ \\
F2 & $\begin{array}{l}\text { Ungu } \\
\text { pekat }\end{array}$ & Agak manis & $\begin{array}{l}\text { Khas buah } \\
\text { harendong }\end{array}$ \\
F3 & $\begin{array}{l}\text { Ungu } \\
\text { pekat }\end{array}$ & $\begin{array}{c}\text { Sangat } \\
\text { manis }\end{array}$ & $\begin{array}{l}\text { Khas buah } \\
\text { harendong }\end{array}$ \\
\hline
\end{tabular}

Pada formula 1, formula 2, formula 3 mendapat hasil warna dan aroma yang sama, yaitu warna ungu pekat yang didapat dari ekstrak buah harendong, dan memiliki aroma khas buah harendong. Sedangkan untuk hasil dari rasa formula 1 memiliki rasa manis yang lebih baik dibanding formula 2. Formula 2 paling kurang manis nya dibanding formula 1 dan 3 . Sedangkan formula 3 memiliki rasa manis paling baik diantara formula yang lainnya. Tetapi dari rasa manis tersebut ada rasa sepat di lidah, karena pada buah harendong mengandung senyawa tanin yang mebuat rasa sepat tersebut (Harbon,1987).

\section{Uji Homogenitas}

Tabel 3. Hasil Uji Homogenitas

\begin{tabular}{cc}
\hline Sirup & Homogenitas \\
\hline F1 & Ada partikel \\
F2 & Homogen \\
F3 & Ada partikel \\
\hline
\end{tabular}

Dari hasil uji homogenitas pada formula 1 terdapat partikel. Partikel tersebut adalah gelatin yang tidak tercampur homogen saat pembuatan, sehingga membentuk partikel seperti gumpalan kecil. Formula 2 tidak terdapat partikel karena tidak menggunakan gelatin sehingga tidak terjadi penggumpalan dari gelatin tersebut. Sedangkan pada formula 3 sama seperti formula 1 terdapat partikel yang disebabkan dari gelatin yang saat pembuatannya terjadi penggumpalan.

\section{Uji Bobot Jenis}

Tabel 4. Hasil Uji Bobot Jenis

\begin{tabular}{ccccc}
\hline Sirup & $\begin{array}{c}\text { Pikno } \\
\text { Kosong }\end{array}$ & Pikno + Air & $\begin{array}{c}\text { Pikno + } \\
\text { Sirup }\end{array}$ & $\begin{array}{c}\text { Bobot } \\
\text { Jenis }\end{array}$ \\
\hline F1 & $9,41 \mathrm{~g}$ & $18,87 \mathrm{~g}$ & $20,12 \mathrm{~g}$ & $1,071 \mathrm{~g} / \mathrm{ml}$ \\
F2 & $10,21 \mathrm{~g}$ & $19,89 \mathrm{~g}$ & $20,61 \mathrm{~g}$ & $1,021 \mathrm{~g} / \mathrm{ml}$ \\
F3 & $11,83 \mathrm{~g}$ & $21,29 \mathrm{~g}$ & $22,29 \mathrm{~g}$ & $1,046 \mathrm{~g} / \mathrm{ml}$ \\
& & & & \\
\hline
\end{tabular}

Uji bobot jenis memiliki tujuan untuk menjamin sediaan memiliki bobot jenis sesuai dengan spesifikasi yang telah di tetapkan dengan menggunakan alat piknometer, bobot jenis sirup kira-kira 1,3 (Depkes RI, 1995). Dari hasil pengujian bobot jenis sirup ekstrak etanol buah harendong (Melastoma malabathricum L.)pada formula 1 mendapat hasil $1,071 \mathrm{~g} / \mathrm{ml}$, pada formula 2 
mendapat hasil $1,021 \mathrm{~g} / \mathrm{ml}$, pada formula 3 mendapat hasil $1,046 \mathrm{~g} / \mathrm{ml}$. Jadi bobot jenis ketiga formula belum memenuhi persyartan mutu bobot jenis yang telah ditetapkan.

\section{Uji Viskositas}

Tabel 5. Hasil Uji Viskositas

\begin{tabular}{cccc}
\hline Sirup & $\begin{array}{c}\text { Waktu Alir } \\
\text { Air }\end{array}$ & $\begin{array}{c}\text { Waktu Alir } \\
\text { Sirup }\end{array}$ & Viskositas \\
\hline F1 & 1,07 detik & 10,64 detik & $11,24 \mathrm{cps}$ \\
F2 & 1,07 detik & 11,07 detik & $11,18 \mathrm{cps}$ \\
F3 & 1,07 detik & 13,03 detik & $13,49 \mathrm{cps}$ \\
\hline
\end{tabular}

Faktor yang mempengaruhi viskositas yaitu, suhu, konsentrasi larutan, berat molekul solute, dan tekanan. Pada pembuatan sirup ekstrak etanol buah harendong (Melastoma malabathricum L.)ada beberapa yang menyebabkan kekentalan sirup tersebut menurun. Ekstrak yang digunakan adalah ekstrak kental, namun saat penyimpanan ekstrak yang tadinya di simpan pada lemari pendingin lalu di keluarkan dan didiamkan beberapa lama ekstrak menjadi cair yang seharusnya ekstrak tetap kental. Saat pengadukan gelatin terjadi gumpalan sehingga sediaan tidak homogen dan partikel tidak terlarut dengan baik, sehingga konsentrasi kelarutan bahan tidak sempurna.

Formula yang lebih kental adalah formula 3 , karena menggunakan bahan pengental gelatin dan Na CMC. Sedangkan formula 1 yang menggunakan bahan pengental gelatin lebih kental daripada formula 2 yang menggunakan bahan pengental $\mathrm{Na}$ CMC. Tetapi dari ketiga formulasi ini tidak ada yang memenuhi ketentuan yang sudah ditetapkan pada Farmakope IV tahun 1995 yang menyebutkan ketentuan viskositas sirup adalah $27 \mathrm{cps}-396 \mathrm{cps}$.

Uji pH

Tabel 6. Hasil Uji pH

\begin{tabular}{ccc}
\hline Sirup & Standar $\mathbf{p H}$ & $\mathbf{p H}$ \\
\hline F1 & $4-7$ & 5 \\
F2 & $4-7$ & 5 \\
F3 & $4-7$ & 5 \\
\hline
\end{tabular}

Dari hasil pengujian $\mathrm{pH}$ diatas bahwa dari masing-masing formula sirup ekstrak etanol buah harendong (Melastoma malabathricum L.)memiliki karakteristik nilai $\mathrm{pH}$ yang baik. Karena $\mathrm{pH}$ yang baik untuk sediaan sirup adalah 4-7 (Depkes RI, 1995). Pada formula 1, formula 2, dan formula 3 mendapatkan nilai $\mathrm{pH} 5$.

\section{SIMPULAN}

Penggunaan gelatin dan natrium carboxymethilcellulose pada sirup antidiare ekstrak etanol buah harendong (Melastoma malabathricum L.) dapat digunakan sebagai pengental meskipun belum memenuhi standar ketentuan. Formula 1 dengan gelatin $3 \%$, formula 2 dengan natrium carboxymethilcellulose $0,3 \%$, formula 3 dengan gelatin $2 \%$ dan natrium carboxymethilcellulose $0,2 \%$. Formula 3 merupakan konsentrasi formula terbaik karena memiliki rasa yang sangat manis, $\mathrm{pH}$ yang yang dihasilkan $\mathrm{pH} 5$, bobot jenis $1,046 \mathrm{~g} / \mathrm{ml}$, dan viskositas $13,49 \mathrm{cps}$. 


\section{REFERENSI}

Arsyad Azhar. (2014). Media Pembelajaran, Jakarta : PT. Rajagrafindo Persada.

Charter JS, 1997, Dispensing for Pharmaceutical Student, Edisi ke-12, Pitman Medical: London10, 186-187.

Depkes RI, (1995). Farmakope Indonesia edisi IV. Departemen Kesehatan Republik Indonesia, Jakarta.

Harborne JB. 1987. Metode Fitokimia. Bandung: Penerbit ITB.

Nash, A. R., (1996). Pharmaceutical Suspensions, in Herbert A. Lieberman, Martin M. Rieger, Gilberts, Banker, Pharmaceutical Dosage Forms : Disperse System, Vol 2,2 ${ }^{\text {nd }}$ Revised and Expanded, New York, pages : 183-188.

Noerasid, N. S., (2003). Gastroenterologi Anak Praktis. Jakarta: Fakultas Kedokteran 